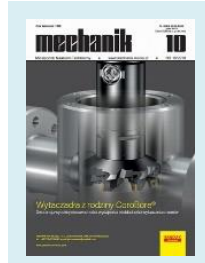

Author: Elżbieta Bączek

How to cite this article:

Title of article: „Właściwości fizyczne, mechaniczne i tribologiczne osnowy w spiekanych narzędziach metaliczno-diamentowych otrzymanych metodami HP i SPS" ("Physical, mechanical properties and wear resistance of iron-base matrix materials for sintered diamond tools fabricated by HP and SPS")

Mechanik, Vol. 91, No. 10 (2018): pages 846-849

DOI: https://doi.org/10.17814/mechanik.2018.10.140

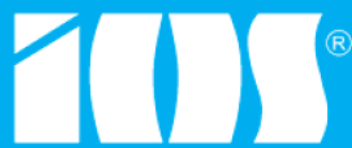

BULLETIN OF THE INSTITUTE OF ADVANCED MANUFACTURING TECHNOLOGY

\title{
Physical, mechanical properties and wear resistance of iron-base matrix materials for sintered diamond tools fabricated by HP and SPS
}

\author{
Właściwości fizyczne, mechaniczne i tribologiczne osnowy w spiekanych \\ narzędziach metaliczno-diamentowych otrzymanych metodami HP i SPS
}

\section{ELŻBIETA BĄCZEK *}

Metal matrix composites were prepared by hot pressing (HP) and spark plasma sintering (SPS) techniques. Ball-milled ironbase powders were consolidated to near full density by these methods at $900^{\circ} \mathrm{C}$. The physical and mechanical properties of the resulting composites were investigated. The specimens were tested for resistance to both 3-body and 2-body abrasion. The composites obtained by HP method (at $900^{\circ} \mathrm{C} / 35 \mathrm{MPa}$ ) had higher density, hardness and resistance to abrasion than those obtained by SPS method.

KEYWORDS: sintered diamond tools, hot pressing, spark plasma sintering, resistance to abrasion

In recent years, there has been an increase in demand for metal and diamond tools used to treat natural stones, concrete, asphalt and abrasive ceramic materials. In the stone industry, the development of these tools was influenced by the creation of a number of private stone mills and increased production of various types of claddings, walls, floors and pavements from such materials as: granite, sandstone, limestone or ceramic tiles. The method commonly used for consolidation of matrix materials in sintered metal-diamond tools is hot pressing (HP), which involves the simultaneous operation of high temperature and pressure, which ensures obtaining almost immediately porousless work rings/segments. As a rule, the isothermal annealing time does not exceed 3 minutes, the sintering temperature depends on the chemical composition of the matrix material and is usually $750 \div 1100^{\circ} \mathrm{C}$, while the pressure is in the range of $25 \div 35 \mathrm{MPa}$.

\footnotetext{
* Mgr inż. Elżbieta Bączek (elzbieta.baczek@ios.krakow.pl) - Instytut Zaawansowanych Technologii Wytwarzania
}

In this method, stress-induced pressures overlap with the stresses resulting from the sintering process itself, thanks to which mass transport mechanisms are intensified. As a consequence, the sintering process is accelerated and a high density material is obtained which is not achievable with free sintering. The classic treatments of powder metallurgy technology, i.e. winter pressing and subsequent sintering of tool working elements, are alternative operations that allow the production of metal-diamond tools [1-5]. The treatment of pressing a mixture of diamond powders, metals constituting the matrix and lubricants is carried out at a pressure of $100 \div 200 \mathrm{MPa}$. If the density of the paraffins is insufficient, hot isostatic pressing (HIP) or in-filtration can be used. The use of the SPS method to consolidate the tool materials allows them to be sintered at a temperature lower by $200 \div 500^{\circ} \mathrm{C}$ and in a much shorter time.

Sintering SPS is one of the most modern methods of consolidating powders. This technique is based on simultaneous application of pressure and current pulses, which can flow through two paths: through stamps and graphite matrix, and by compacted powder grains. The time of material heating along with its isothermal sintering is usually $5 \div 20 \mathrm{~min}$. In addition, in the SPS process, high material heating rates of up to $1000^{\circ} \mathrm{C} / \mathrm{min}$ can be used. This allows sintering of nanocrystalline powders without the effect of grain growth [6-13].

In comparison with the isostatic hot pressing method, the demand for electricity in the SPS process is about $20 \div 30 \%$ lower, which is very important for economic reasons.

The research was carried out in connection with the growing market demand for metallic and diamond tools intended for the treatment of stonework materials. The main aim of the work was to examine the influence of various sintering techniques on selected physical, mechanical and 
tribological properties of the matrix material, which is an alternative to the commonly used Co- $20 \%$ WC sinters.

\section{Methodology and research results}

Samples for testing were made of elemental iron powders of the species NC100.24 from Höganäs, ground powders of ferro-manganese from $\mathrm{XH} 1218$ and $\mathrm{XH} 1210$ from ESAB and water-sprayed bronze powder of tin, $20 \%$ Sn from grade NAM40-80/20 NEO CHIMIE.

The characteristics and morphology of powders used for the tests are presented in the tab. I and in SEM pictures (fig. 1). The mean particle size was determined by the sieve analysis method, and the percentage shares of particular grain fractions were determined according to the PN-EN 24497: 1999P standard. Powder test results are presented in the form of a cumulative curve in fig. 2.

TABLE I. Chemical composition and particle size of starting powders (determined by sieve analysis)

\begin{tabular}{|c|c|c|c|c|c|c|c|}
\hline \multirow[b]{2}{*}{ Powder grade } & \multirow[b]{2}{*}{ Producer } & \multicolumn{5}{|c|}{ Elements contents, \% mas. } & \multirow{2}{*}{$\begin{array}{l}\text { Average } \\
\text { particle } \\
\text { size, } \mu m\end{array}$} \\
\hline & & $\mathrm{Fe}$ & $\mathrm{Mn}$ & $\mathrm{Cu}$ & Sn & C & \\
\hline NC100.24 & Höganäs & 100 & - & - & - & - & 85 \\
\hline $\mathrm{XH} 1210$ & ESAB & 13 & 80 & - & - & 7.0 & 134 \\
\hline $\mathrm{XH} 1218$ & ESAB & 18 & 80.5 & - & - & 1.5 & 143 \\
\hline NAM40-80/20 & $\begin{array}{c}\text { NEO } \\
\text { CHIMIE }\end{array}$ & - & - & 80 & 20 & - & 23 \\
\hline
\end{tabular}

a)

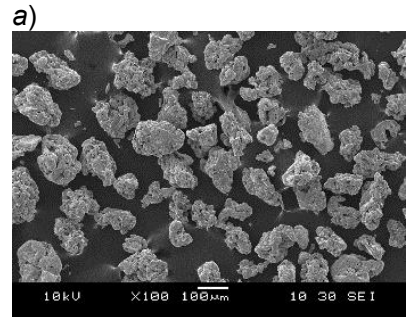

c)

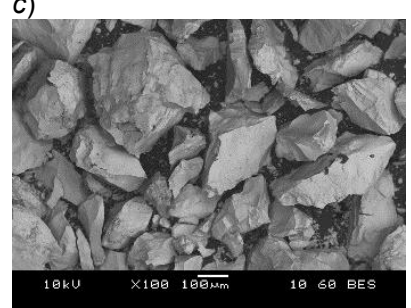

Fig. 1. Powders used for testing: a) iron NC100.24, b) high-carbon ferromanganese $\mathrm{XH} 1210, c)$ low-carbon ferromanganese $\mathrm{XH} 1218$, d) tin bronze NAM40-80/20

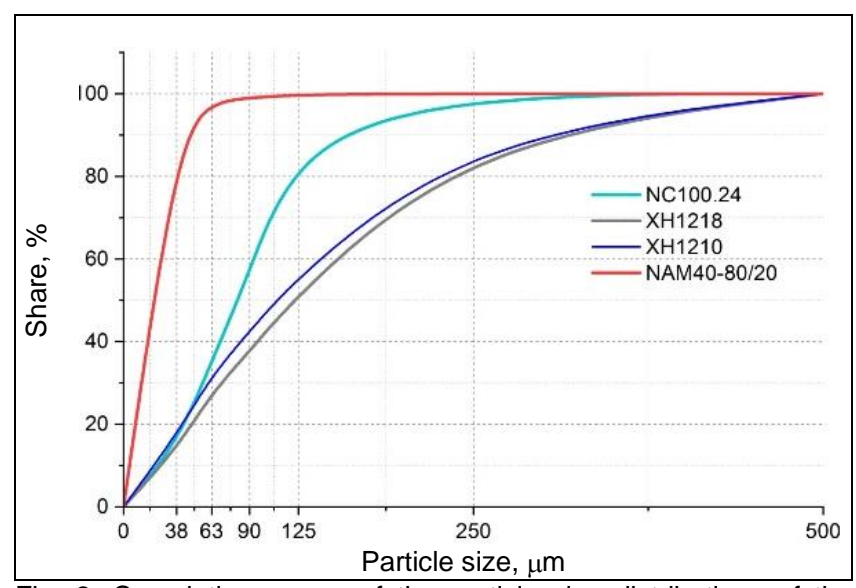

Fig. 2. Cumulative curves of the particle size distributions of the starting powders

A Turbula T2C mixer was used to prepare the powder blends. The powders were mixed for $10 \mathrm{~min}$. The mass shares of individual powders were respectively: $77 \%$ NC100.24, 7.5\% XH1210, 7.5\% XH1218 and 8\% NAM40-
$80 / 20$. The prepared powder mixtures were grinded in a ball mill for 8,30 and 120 hours, in an atmosphere of air, in a container filled in $50 \%$ volume with balls of $12 \mathrm{~mm}$ in diameter made of $100 \mathrm{Cr} 6$ steel. The ratio of the mass of the balls to the mass of ground powder was 10:1. The rotational speed of the drum reached approx. $70 \%$ of the critical speed. The following determinations were made: mixtures of powders milled for 8,30 and $120 \mathrm{~h}$ were marked with numbers 008, 030 and 120 respectively. The average particle size of ground powder mixtures was determined by sieve analysis (fig. 3). The microstructure of ground powder mixtures is shown in SEM images (fig. 4).

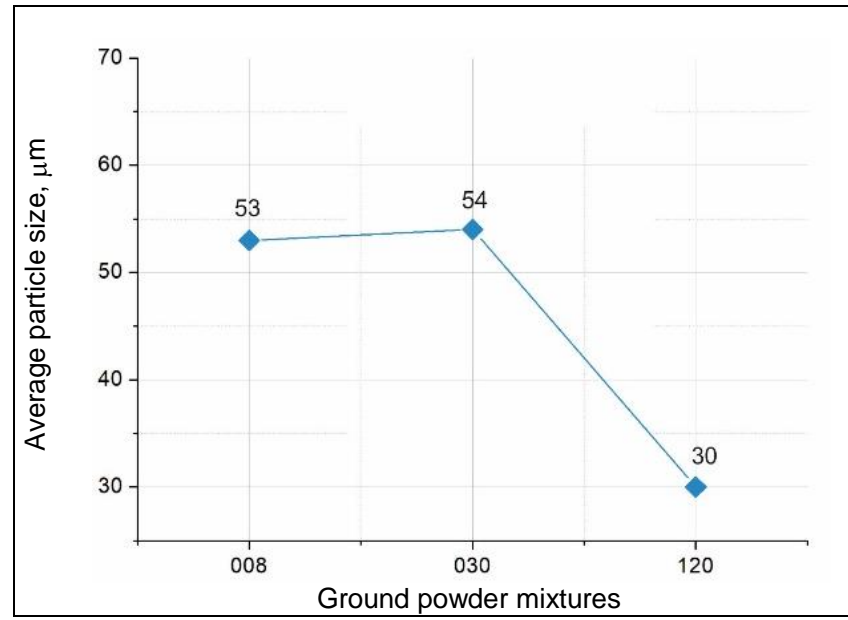

Fig. 3. Average particle size of powders depending on the time of the milling
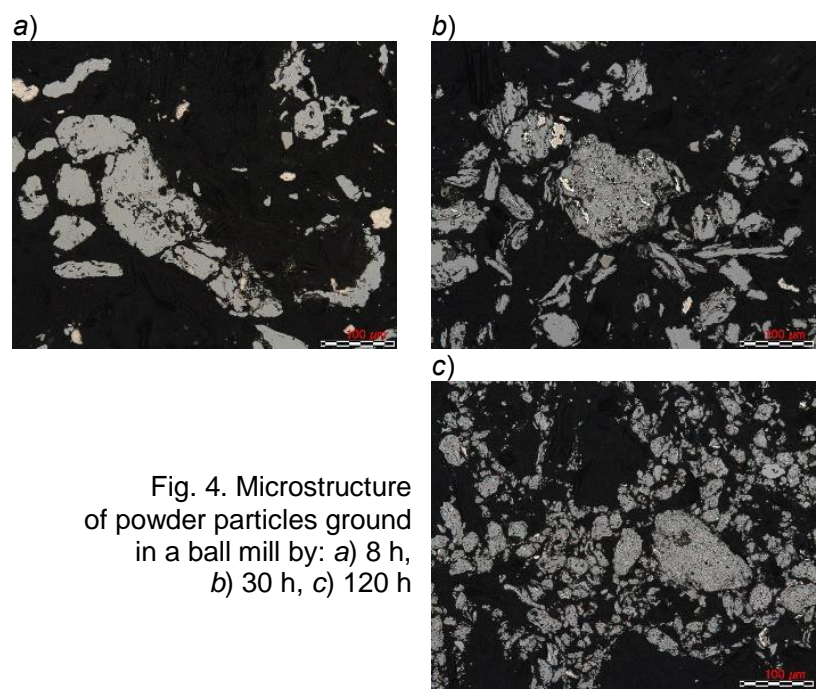

Mixtures of powders milled for 8,30 and $120 \mathrm{~h}$ were consolidated using the SPS and HP methods in a graphite matrix, using the FCT SPS HP 5 device (fig. 5a) and the Idea Unidiamond blast furnace (fig. $5 b$ ).

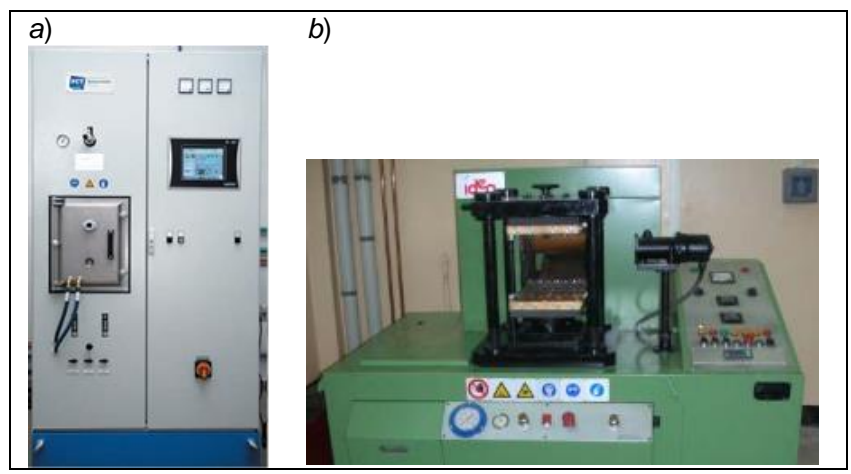

Fig. 5. Devices for sintering composites: a) SPS HP 5 from FCT, b) Idea-unidiamond from Idea 
The powders were heated to $900^{\circ} \mathrm{C}$ and were kept at this temperature for $3 \mathrm{~min}$ and then cooled to ambient temperature. The pressing pressure during baking at sintering temperature was $35 \mathrm{MPa}$. Examples of sintering process runs for both methods are shown in fig. 6 .

All sinters obtained were subjected to measurements of: density (by weighing in air and water), Vickers hardness (HV1) and bending strength. The results are shown in fig. 7 and fig. 8 and in the table II. Examples of bending curves for material obtained by SPS and HP from a mixture of powders ground for 8 hours are shown in fig. 9.

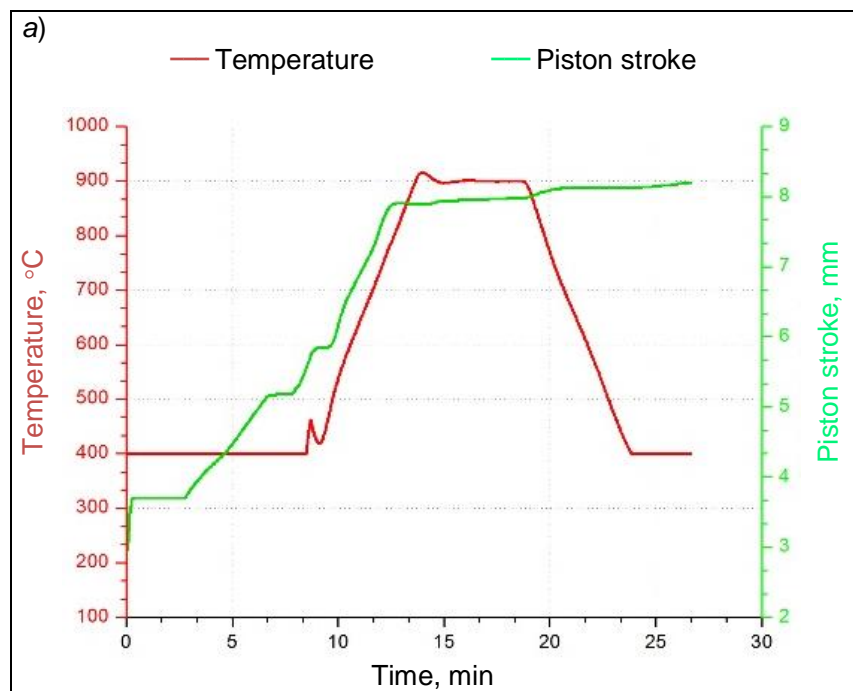

b)

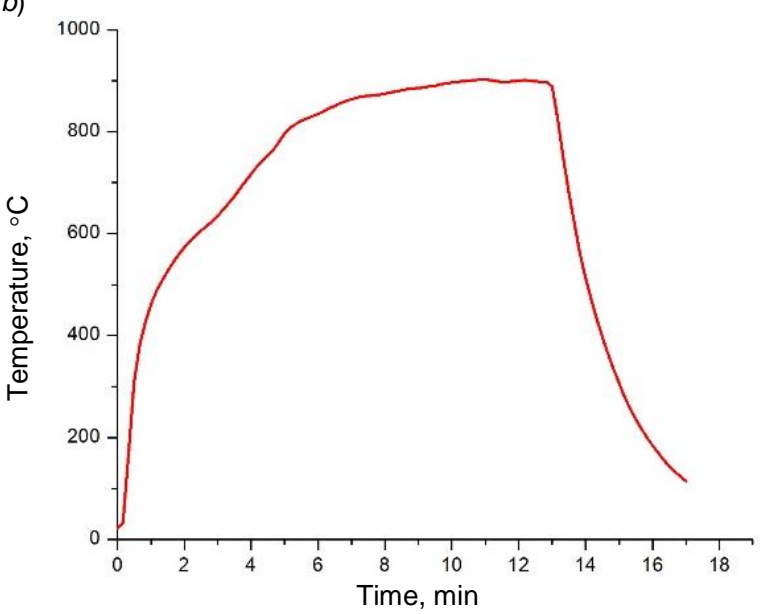

Fig. 6. Examples of the consolidation process using the method a) SPS, b) HP

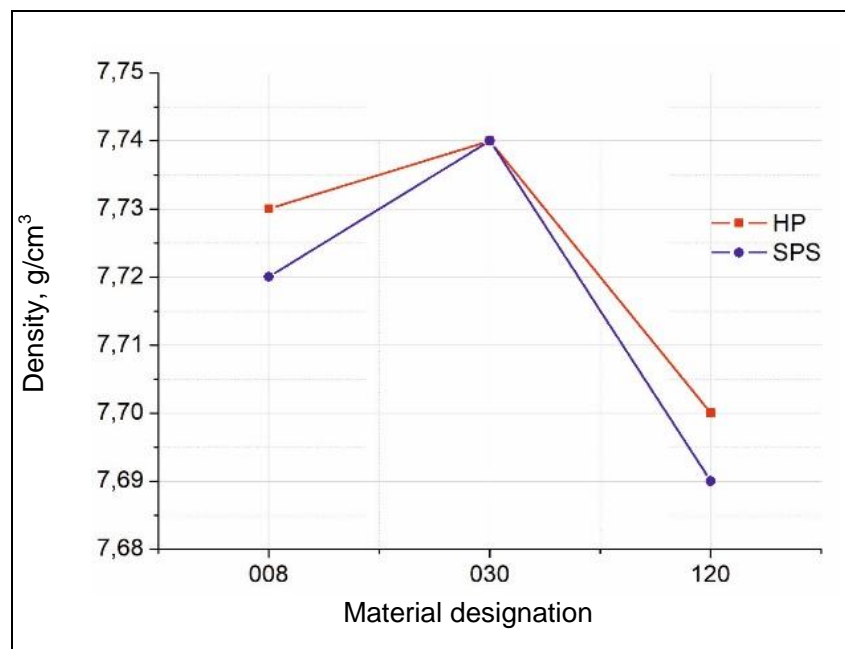

Fig. 7. Density of sinters obtained by SPS and HP methods from ground powder mixtures

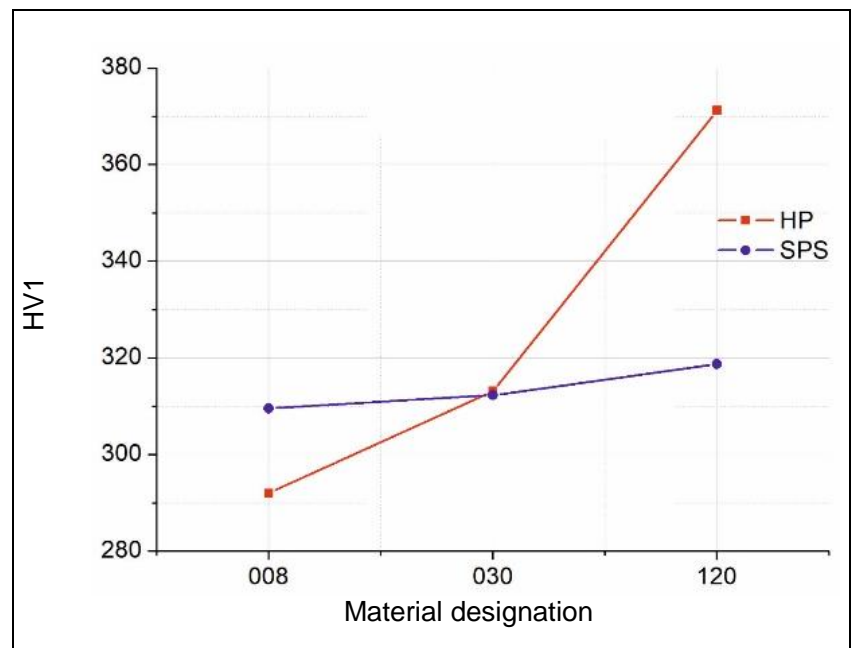

Fig. 8. Hardness of HV1 sinters obtained by SPS and HP methods from mixed powder blends

TABLE II. Average values of three-point bending test results

\begin{tabular}{|c|c|c|c|c|}
\hline $\begin{array}{c}\text { Consolidation } \\
\text { method }\end{array}$ & $\begin{array}{c}\text { Material } \\
\text { designation }\end{array}$ & $\begin{array}{c}\text { Bending } \\
\text { strength } \\
R_{\mathrm{g}}, \mathrm{MPa}\end{array}$ & $\begin{array}{c}\text { Conventional } \\
\text { limit of plasticity } \\
\sigma_{\mathrm{g} 0,2}, \mathrm{MPa}\end{array}$ & $\begin{array}{c}\text { Plastic } \\
\text { deformation } \\
\varepsilon_{\mathrm{g}} \%\end{array}$ \\
\hline \multirow{3}{*}{$\mathrm{HP}$} & 008 & 1223 & 904 & 3.40 \\
\cline { 2 - 5 } & 030 & 1243 & 927 & 2.78 \\
\cline { 2 - 5 } & 120 & 1417 & 1333 & 0.67 \\
\hline \multirow{3}{*}{ SPS } & 008 & 1065 & 803 & 1.39 \\
\cline { 2 - 5 } & 030 & 1032 & 788 & 1.41 \\
\cline { 2 - 5 } & 120 & 1268 & 1197 & 0.64 \\
\hline
\end{tabular}

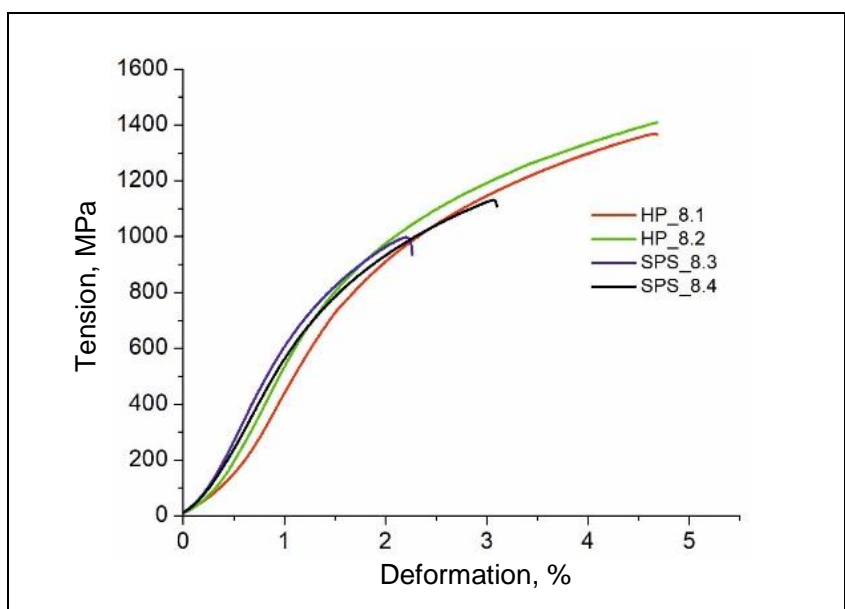

Fig. 9. Curves obtained in a three-point bending test of samples obtained by SPS and HP methods from a mixture of powders ground for 8 hours

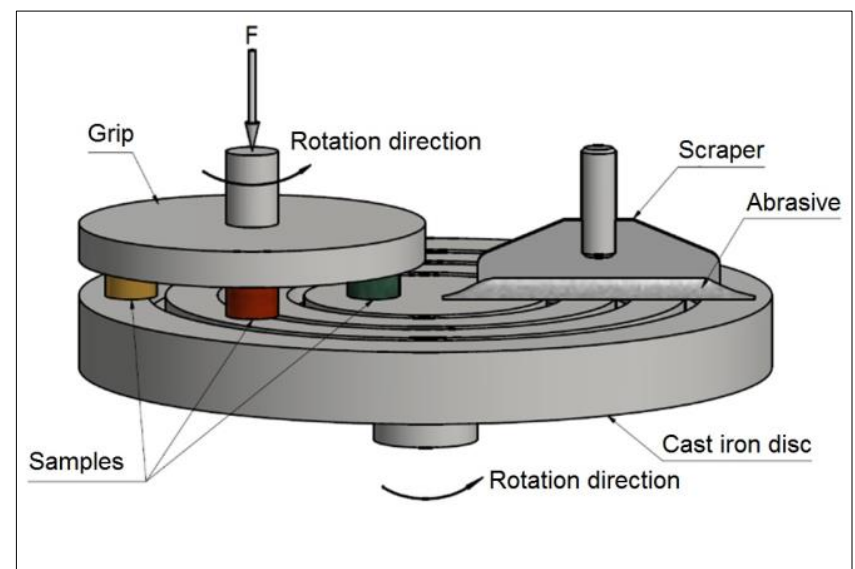

Fig. 10. Scheme of the device for measuring the resistance of sinters to abrasive wear by the MWT method, abrasive wear in the presence of three bodies (Ai3) 
The abrasion resistance tests were carried out in the presence of three bodies (Ai3) - using the Micro Wear Test method [12-14] - and in the presence of two bodies (Ai2), in accordance with the procedure developed at AGH [15]. Scheme of the stand for testing resistance to abrasive wear using the MWT method is shown in fig. 10.

The results of abrasion resistance tests are presented in table III, in which, moreover, these results were compared with the Co-20\% WC reference material, commonly used for the production of sintered diamond-metal tools.

TABLE III. Averaged value of abrasive wear of sinters obtained by SPS and HP methods from powders milled for 8,30 and 120 $h$ and reference material $\mathrm{Co}-20 \%$ WC in the presence of two and three bodies

\begin{tabular}{|c|c|c|c|}
\hline $\begin{array}{c}\text { Consolidation } \\
\text { method }\end{array}$ & $\begin{array}{c}\text { Material } \\
\text { designation }\end{array}$ & $\begin{array}{c}\mathrm{A}_{\mathrm{i} 3}, \\
\mu \mathrm{m} / 20 \mathrm{~m}\end{array}$ & $\begin{array}{c}\mathrm{A}_{\mathrm{i} 2}, \\
\mu \mathrm{m} / 20 \mathrm{~m}\end{array}$ \\
\hline \multirow{3}{*}{$\mathrm{HP}$} & 008 & 23,2 & 163.2 \\
\cline { 2 - 4 } & 030 & 26,0 & 170.1 \\
\cline { 2 - 4 } & 120 & 28,4 & 210.7 \\
\hline \multirow{3}{*}{ SPS } & 008 & 33,0 & 170.2 \\
\cline { 2 - 4 } & 030 & 34,7 & 164.8 \\
\cline { 2 - 4 } & 120 & 38,8 & 220.2 \\
\hline \multirow{2}{*}{ HP } & Co-20\%WC & 33,6 & 98.0 \\
\hline
\end{tabular}

\section{Analysis of results}

As part of the conducted tests, the usefulness of various consolidation methods in the process of obtaining sintered metal-diamond tools for processing natural stone, concrete, asphalt and other abrasive building materials was confirmed. It has been shown that the shorter grinding time, i.e. 8 and $30 \mathrm{~h}$, does not cause a clear change in the average particle size of the powders, which is $53 \mu \mathrm{m}$ and 54 $\mu \mathrm{m}$, respectively. Extending the grinding time to 120 hours results in a reduction of the average particle size to $30 \mu \mathrm{m}$. On the basis of microscopic observation (SEM) it was found that powders milled for $8 \mathrm{~h}$ have a flake shape. With the lengthening of milling time, the particles are subject to intensive crushing. Their size is reduced and the shape changes from flaky to even-axial. Measurements of sinter density (fig. 7) showed that in both methods it is possible to densify all tested powder mixtures to a relative density above $97 \%$, which corresponds to an apparent density in the range of $7.69 \div 7.74 \mathrm{~g} / \mathrm{cm}^{3}$. The analysis of the density measurements of individual mixtures confirmed the reduction of the apparent density of the materials along with the prolongation of the grinding time, which may be caused by the progressive oxidation of powders. All sinters were subjected to Vickers hardness testing. Regardless of the method of consolidation used, the lowest hardness was determined by materials made of powdered powders for 8 hours (fig. 8). Along with the prolongation of the grinding time of the blends, a marked increase in the hardness of the fractions was observed, which results from the higher microstructure fragmentation and the strengthening of the oxide phase. Hardness is characterized by materials obtained by HP. The results of the three-point bending test (tab. II and fig. 9) indicate a clear relationship between the grinding time and the yield point and the plastic deformation size of the samples at the time of fracture. The flexural strength of the materials obtained with the HP and SPS methods from powder mixes milled for 8 and $30 \mathrm{~h}$ was very similar and was respectively: $1223 \mathrm{MPa}$ and $1243 \mathrm{MPa}$ for the HP method and $1065 \mathrm{MPa}$ and $1032 \mathrm{MPa}$ for the SPS method. Extending the grinding time to 120 hours resulted in a very pronounced increase in bending strength and yield strength (up to $1417 \mathrm{MPa}$ and $1333 \mathrm{MPa}$ for the HP method and $1268 \mathrm{MPa}$ and $1197 \mathrm{MPa}$ for the SPS method) at the expense of reducing the plastic properties of the material $\left(\varepsilon_{\mathrm{g}}\right.$ $<1 \%$ ). The increase in the conventional yield strength of powdery materials grounded for $120 \mathrm{~h}$ may result from a significant reduction in grain size, as well as from the strengthening of the oxide phase.

Tests of resistance of abrasive material in abrasive wear in the presence of three bodies, carried out using the MWT method, showed that sinters produced by HP method from ground powder mixtures based on iron, ferromanganese and tin bronze reduced in powders are characterized by much higher resistance for abrasive wear than the commonly used Co- $20 \%$ WC sinters. In the case of abrasion resistance tests in the presence of two bodies, the best results were obtained for Co- $20 \%$ WC sinters. It should be added that the high abrasion resistance of these materials is the result of a high content of hard carbide phase. It was also observed that, irrespective of the method of consolidation used, the resistance of Fe-Mn-Cu-Sn-C sinters to abrasive wear is reduced along with the increase of grinding time.

\section{Conclusions}

- By grinding and consolidating SPS and HP mixtures of powders of iron, ferromanganese and cine bronze, you can obtain a material with good durability properties, plastic and tribological, similar to the properties of Co- $20 \%$ WC.

- Consolidation (at $900^{\circ} \mathrm{C}$, for 3 minutes at $35 \mathrm{MPa}$ ) of powders milled for 8,30 and $120 \mathrm{~h}$ allows obtaining materials with a relative density above $97 \%$.

- Powder grinding time significantly affects the mechanical properties of the obtained materials. Extending the grinding time decreases the grain size and homogenization of the chemical composition of the sinter.

- Extending the grinding time of the starting powders results in a marked increase in the hardness and yield strength of the sinters at the expense of a decrease in plastic properties.

- Improvement of strength properties and hardness of sintered materials results from grain refinement and strengthening with an oxide phase.

- The sintered powder obtained by HP from powder milled for 8 hours has the highest abrasion resistance in all three materials in the presence of three bodies.

The results of the research clearly show that both methods of consolidation of mixtures of powdered powders based on tapes, elementary powders can be successfully used for the production of metallic-diamond sinters. They allow to obtain cheap materials that can successfully replace commonly used, expensive and deficient powders of cobalt and tungsten carbide.

Works carried out under the PRELUDIUM 10 UMO2015/19/N/ST8/01050 grant, financed by the National Science Center. 


\section{REFERENCES}

1. Konstanty J. "Powder Metallurgy Diamond Tools". Oxford: Elsevier, 2005.

2. Konstanty J. "Cobalt as a matrix in diamond impregnated tools for stone sawing applications". 2003.

3. Konstanty J., Bunsch A. "Hot pressing of cobalt powders". Powder Metall. 34 (1991): pp. 195-198.

4. Tillmann W., Kronholz C., Ferreira M., Knote A., Theisen W., Schütte P. "Comparison of Different Metal Matrix Systems for Diamond Tools Fabricated by New Current Induced Short-Time Sintering Processes". PM2010 World Congr. Diam. Tools. Manuscr. Ref. by Dr José M Sanchez, CEIT, Spain, 2010.

5. Schmidt J., Knote A., Armbrüster M., Weißgärber Th. "Spark Plasma Sintering of Diamond Impregnated Wire Saw Beads". Diam. Appl. Technol. 64 (2011): pp. 35-40.

6. Handtrack D., Despang F., Kieback B., Reinfried N., Grin Y. "Fabrication of ultra-fine grained and dispersion-strengthened titanium materials by spark plasma sintering". Mater. Sci. Eng. 437 (2006): pp. 423-429.

7. Schmidt J., Weißgärber Th, Schubert T. "Spark Plasma Sintering of Intermetallics and Metal Matrix Composites". Euro PM2005 Sinter. II. 2005.

8. Yunga D-L., Cygan S., Antonova M., Jaworska L., Hussinova I. "Ultra high-pressure spark plasma sintered $\mathrm{ZrC}-\mathrm{Mo}$ and ZrC-TiC composites". Int. J. Refract. Metals Hard Mater. 16 (2016): pp. 201-206.

9. Luo C., Qi Y., Pan C., Yang W. "Diamond synthesis from carbon nanofibers at low temperature and low pressure". Nat. Publ. Gr. (2015): pp. 1-6 (DOI: 10.1038/srep13879).

10. Grasso S., Hu Ch., Maizza G., Sakka Y. "Spark plasma sintering of diamond binderless WC composites". J. Am. Ceram. Soc. 95 (2012): pp. 2423-2428 (DOI: 10.1111/j.1551-2916.2011.05009.x).

11. Zhou X., Wang Y., Li T., Li X. I in. "Fabrication of diamond-SiC-TiC composite by a spark plasma sinteringreactive synthesis method". J. Eur. Ceram. Soc. 35 (2015): pp. 69-76 (DOI: 10.1016/j.jeurceramsoc.2014.08.006).

12. Micro Wear Test-Instruction Manual (Struers Tech, Denmark 1989).

13. Fundal E. "Consuliting-Labormat amba, Application of the LABORMET lapping and micro wear testing".

14. Fundal E. "Consulitng, Abrassive wear mapping using the Micro Wear Test".

15. Konstanty J. "Testing resistance to abrasive wear of iron-base materials used as metallic matrices in diamond impregnated tool components. Final Report, February 2007'. (unpublished, made on behalf of Diamond Ind. Co Ltd., Osan, South Korea).

Translation of scientific articles, their computer composition and publishing them on the website www.mechanik.media.pl by original articles in Polish is a task financed from the funds of the Ministry of Science and Higher Education designated for dissemination of science. 